TAP CHÍ KHOA HỌC ĐẠI HỌC TÂN TRÀO
ISSN: 2354 - 1431

\title{
Tác động của tín ngưỡng trong đời sống tâm linh của cư dân ở nội thành Hà Nội hiện nay
}

\author{
Vũ Trưòng Giang ${ }^{a}$ * \\ ${ }^{a}$ Học viện Chính trị khu vục I \\ *Email: giangnhanhoc@yahoo.com.vn
}

\section{Thông tin bài viết}

Ngày nhận bài:

01/6/2018

Ngày duyệt đăng:

10/12/2018

\section{Tù khoá:}

Tác động; tín nguõng; đò̀ sống; tâm linh; Hà Nọi.

\section{Tóm tắt}

Những giá trị truyền thống tốt đẹp trong hoạt động tôn giáo, tín ngưỡng ở Hà Nội vẫn được duy trì, tuy nhiên cũng nảy sinh không ít bất cập. Bài viết giới thiệu một số cơ sở thờ tự và thực hành tín ngưỡng ở Hà Nội; phân tích tác động và ảnh hưởng của tín ngưỡng trong đời sống của cư dân ở Hà Nội hiện nay.

\section{1. Đặt vấn đề}

Thăng Long - Hà Nội nằm ở trung tâm của vùng châu thổ sông Hồng, nơi lưu giữ rất nhiều giá trị văn hóa cổ truyền của dân tộc. Không gian tâm linh ở Hà Nội hết sức phong phú và độc đáo với kết cấu ba vòng: Vòng ngoài, làng xã ngoại thành rộng lớn, tiêu biểu cho loại hình làng xã của văn minh sông Hồng. Vòng trong, "Thăng Long tứ trấn" với những di tích lịch sử, tôn giáo, tín ngưỡng đã khá tập trung đậm đặc. Vòng trong cùng, vòng xoáy của không gian tâm linh, đó là khu vực Hoàng thành - khu phố cổ Hà Nội, nơi tập trung nhất của không gian tâm linh, tôn giáo gắn kết với không gian quyền lực chính trị - xã hội.

Trong cái không gian tâm linh ấy, các cơ sở thờ tự của mọi loại hình tôn giáo tín ngưỡng đều được người dân, các chính quyền qua các thời đại tính toán sắp đặt, vun đắp và bảo tồn qua biết bao thế hệ và tự nó đã tạo nên những giá trị văn hóa vật thể, văn hóa phi vật thể không thể tách rời với lịch sử và hiện tại của thành phố ${ }^{(1)}$.

${ }^{1}$ Xem Đỗ Quang Hưng: "Không gian thiêng của Thăng Long - Hà Nội”, Báo cáo tại Hội thảo khoa học quốc tế "Phát triển bền vũngThủ

\section{Một số cơ sở thờ tự và thực hành tín ngưỡng ở} Hà Nội

\subsection{Thăng Long tứ trấn}

Theo quan niệm của người Việt, trời đất có bốn phương Đông, Tây, Nam, Bắc thì thành Thăng Long cũng phải có “tứ trấn", được xây dựng với bốn ngôi đền, trong đó đều có một vị thần đầy quyền uy canh giữ cho kinh thành từ Thăng Long thời xưa đến Hà Nội hiện nay.

\section{- Đền Bạch Mã ở hướng Đông}

Đền Bạch Mã toạ lạc tại phường Hà Khẩu, tổng Đông Thọ, phủ Hoài Đức, Thăng Long (nay là phường Hàng Buồm, quận Hoàn Kiếm). Đền Bạch Mã thờ thần Long Đỗ, đó là thần thành hoàng đầu tiên của Thăng Long, nằm ven sông Tô Lịch, ít nhất cũng đã xuất hiện từ thế kỷ $\mathrm{IX}$, khi Cao Biền đắp thành Đại $\mathrm{La}$. Thời nhà Lý, đền Bạch Mã trở thành một trung tâm sầm uất của lễ hội Thăng Long và sinh hoạt cung đình.

- Đền Voi Phục ở hướng Tây

đô Hà Nội văn hiến, anh hùng, vì hòa bình", Hà Nội, ngày 7,8,9 tháng 10 năm 2010. 
Đền Voi Phục thờ thần Linh Lang đại vương, người đã giúp nhà Vua đánh tan quân Tống sang xâm lược nước ta trên vùng đất Thăng Long. Tương truyền, đền Voi Phục được xây dựng năm Chương Thánh Gia Khánh thứ 7 (năm 1065) đời vua Lý Thánh Tông trên một khu gò cao thuộc đất của trại Thủ Lệ - một trong 13 làng trại ở phía tây kinh thành Thăng Long. Thời Pháp đánh Hà Nội (1873 - 1883), quân dân Hà Nội đã diệt hai tướng Pháp F. Garnier và $H$. Rivière ở khu vực này. Tên đền Voi Phục có từ thời ấy vì cổng đền đắp nổi hai con voi phục, quỳ xuống để thần Linh Lang bước lên mình voi như chiến tướng ra trận.

\section{- Đền Kim Liên ở hướng Nam}

Đền Kim Liên được xây dựng dưới thời vua Lý Thái Tổ ngay khi vị hoàng đế này rời đô tới Thăng Long, với mục đích để bảo vệ kinh thành mới ở hướng Nam. Tương truyền thần Cao Sơn là con trai Lạc Long Quân và được thờ là vị thần thứ hai trong đền núi Tản Viên. Thần đã có công giúp Sơn Tinh chiến thắng Thủy Tinh và sau này giúp vua Lê Tương Dực dẹp loạn, khôi phục nhà Lê.

Đền Kim Liên xưa thuộc phường Đông Tác, huyện Thọ Xương, phủ Hoài Đức. Kim Liên, tên cũ là làng Kim Hoa, gọi nôm là Đồng Lầm, vì phải kiêng húy tên của bà mẹ vua Thiệu Trị là Hồ Thị Hoa nên đổi là Kim Liên sau là tổng Kim Liên. Đền Kim Liên nay thuộc phường Kim Liên, quận Đống Đa.

\section{- Đền Quán Thánh ở huớng Bắc}

Đền được lập từ khi Lý Thái Tổ dời đô về Thăng Long (1010). Vua cho rước bài vị của thần về ở phía Tây Bắc thành, gọi là Huyền Thiên Trấn Vũ đại đế quán. Quán là nơi thờ tự của đạo Giáo, dân chúng quen gọi là đền Trấn Vũ hoặc đền Quán Thánh. Thời Lê thuộc đất phường Thụy Chương, huyện Vĩnh Thuận, phía Nam Hồ Tây, nay ở ngã tư đường Thanh Niên và đường Quán Thánh, thuộc phường Quán Thánh, quận Ba Đình. Không chỉ là một công trình có giá trị về mặt lịch sử và kiến trúc, đền Quán Thánh còn là nơi sinh hoạt tín ngưỡng văn hóa nổi tiếng của người dân Hà Nội xưa và nay. Trải qua gần một thiên niên kỷ nhưng ngôi đền vẫn còn nguyên vẹn.

\subsection{Thờ thành hoàng}

\section{- Đinh Kim Mã}

Đình ở phố Kim Mã và cũng mang tên làng cổ Kim Mã - một trong "Thập Tam Trại” (13 trại). Đình được lập từ thế kỷ 11 ở phía Tây của kinh thành Thăng Long. Vào thời Lý - Trần, đất làng Kim Mã được dùng làm nơi nuôi ngựa của Hoàng cung, nên còn gọi là "Tầu Mã" hay "Mã trại". Đình Kim Mã thờ ba vị Thành hoàng là Bố cái đại vương, Linh Lang đại vương và Thái tể Hoàng Phúc Trung - những nhân vật có liên quan trực tiếp đến các sự kiện lịch sử lớn trong vùng và là nguồn gốc của sự xuất hiện của cộng đồng dân cư ở nơi này.

\section{- Đình Mai Động}

Đình Mai Động nằm ở phía bên trong ngõ 254 phố Minh Khai, quận Hai Bà Trưng. Đình Mai Động thờ Đô vật Tam Trinh, thầy dạy chũ̃, dạy võ và vật không chỉ cho trai tráng trong làng mà cả các vùng lân cận. Ông Tam Trinh vốn là người gốc Thanh Hoá đã đến Mai Động sinh sống và dạy học. Sau ông trở thành thủ lĩnh nghĩa quân trong vùng và hợp tác trong cuộc khởi nghĩa của Hai Bà Trưng. Ông từng lập nhiều chiến công vào năm 40 và được Hai Bà Trưng phong Tướng. Năm 43, khi Hai Bà Trưng tuẫn tiết, ông vẫn cố thủ ở Mai Động, chiến đấu đến cùng và hy sinh vì nghĩa lớn.

\section{- Đình Thành Công}

Đình Thành Công ở số 6 phố Thành Công, quận Ba Đình. Hậu cung của đình bị tách ra bởi ngõ ngõ $6 \mathrm{~A}$ phố Thành Công. Tại hậu cung thờ bốn người có khắc tên trên bia Tiến sĩ tại Văn miếu Quốc Tử Giám: Đỗ Kim Oánh, Nguyễn Đắc Vinh, Nguyễn Đăng Long, Trương Đình Tuyên và thờ Chủ tịch Hồ Chí Minh cùng các liệt sĩ trong hai cuộc kháng chiến. Theo các vị cao niên ở đây kể lại thì đình có từ đời Lý Thần Tông (11281138). Sau khi chùa Láng xây xong thì đình Nhược Công (nay là đình Thành Công) cũng được xây dựng.

\section{- Đinh Cur Chính}

Đình Cự Chính còn gọi là đình Con Cóc (do trước kia trên hai trụ trước đình có gắn hai tượng cóc bằng sứ) ở thôn Cự Chính (tên Nôm là làng Mọc), phường Nhân Chính, quận Thanh Xuân. Đình Cự Chính cách chùa Bồ Đề chừng vài chục mét. Đình Cự Chính xây dựng vào thời Lê và đã được tu sửa nhiều lần. Đình thờ thành hoàng là Lã Đại Liêu, tướng của thần Tản Viên, có công giúp vua Hùng đánh giặc giữ nước.

\subsection{Thờ tổ nghè}

- Đình Xuân Phiến tại số 4 Hàng Quạt thờ ông họ Đào - tổ nghề làm quạt của dân làng Ân Thi - Hải Dương.

- Đình Kim Ngân tại số 42 Hàng Bạc thờ Hoàng đế Hiên Viên, một nhân vật có tính chất thần thoại được coi là ông tổ của bách nghệ. 
- Đình Phả Trúc Lâm (số 40 phố Hàng Hành) và đình Hài Tượng (số 16 ngõ Hài Tượng) thờ Tiến sĩ Nguyễn Thời Trung - tổ nghề thuộc da, đóng hia hài, các ông Thuần Chính, Đức Chính, Sĩ Bân (tổ nghề da giày) ở làng Chắm (Gia Lộc - Hải Dương).

- Đình Hài Tích (số 1 phố Lò Rèn) thờ Phạm Nguyệt, Nguyễn Nga, Nguyễn Cẩn Thánh sư - là các vị tổ sư nghề rèn, gốc ở làng Hòe Thị, Xuân Phương, Từ Liêm.

- Đình Hà Vỹ (số 11 phố Hàng Hòm) thờ ông tổ nghề sơn son, thiếc vàng là Trần Lư (1470-1540) quê làng Bình Vọng, Thường Tín, đỗ Tiến sĩ năm 1502.

- Đình Ngũ Xã thờ ông tổ sư nghề đúc đồng Minh Không. Ông tên thật là Nguyễn Chí Thành (1066 1141) là nhà sư nổi tiếng thời Lý, người làng Đàm Xá, huyện Gia Viễn, tỉnh Ninh Bình. Ngũ Xã là năm xã Đông Mai, Châu Mỹ, Long Thượng, Đào Viên và Điện Tiền ở vùng Thuận Thành (Bắc Ninh) và Văn Lâm (Hưng Yên). Vào khoảng thế kỷ 17 - 18, một số thợ đúc đồng quê ở năm xã kia đã cùng nhau về bán đảo Trúc Bạch (nay thuộc quận Ba Đình) mở lò đúc đồng nên có tên là Ngũ Xã.

\subsection{Thò̀ mẫu}

\section{- Đền Nghĩa Lập}

Đền Nghĩa Lập ở 32 Hàng Đậu. Tương truyền đền thờ Tứ vị Hồng Nương - những bà Thánh trợ giúp người đi sông biển (thôn Nghĩa Lập ở sát sông Hồng). Hiện nay, căn cứ vào sinh hoạt của đền thì đối tượng thờ là mẫu Tứ phủ, Tam phủ.

\section{- Đền Cổ Lương}

Đền Cổ Lương ở số nhà 28 phố Nguyễn Siêu, phường Hàng Buồm, quận Hoàn Kiếm, Hà Nội. Đền Cổ Lương thờ công chúa Liê̂u Hạnh hay Mẫu Liễu. Với kiến trúc còn nguyên vẹn cùng cảnh quan bên ngoài khá đẹp, đền Cổ Lương ở trong khu phố cổ sẽ là điểm dừng chân lý thú cho khách tham quan trong và ngoài nước khi đến với thủ đô Hà Nội.

\section{- Phủ Tây Hồ}

Phủ Tây Hồ là cơ sở thờ mẫu lớn nhất ở Hà Nội. Phủ Tây Hồ và đền Kim Ngưu thuộc thôn Tây Hồ, nay là phường Quảng An, quận Tây Hồ, Hà Nội. Phần thờ tự theo thứ tự từ ngoài vào: Lớp thứ nhất, thờ Tam phủ công đồng, Tứ phủ vạn linh và Hội đồng các quan, có tượng ông Hoàng Bảy, Hoàng Mười, 3 đôi câu đối ca ngợi chúa Liễu Hạnh. Lớp thứ hai, thờ Ngọc Hoàng và Nam Tào, Bắc Đẩu, có câu đối ca ngợi thắng cảnh Tây Hồ. Lớp thứ ba thờ Tam Tòa Thánh Mẫu có cửa võng đề "Tây Hồ phong nguyệt" và đôi câu đối ca ngợi bà Liễu Hạnh. Trên nóc mái giáp cửa hậu treo đại tự "Mẫu nghi thiên hạ", hai bên có câu đối bằng gỗ. Lớp trên cùng, hậu cung là nơi đặt tượng của bà Liễu Hạnh và tượng Chầu Quỳnh, Chầu Quế. Trên cao là bức đại tự "Thiên tiên trắc giáng" và "Mẫu nghi thiên hạ".

\section{5. Điện thờ tu' gia}

Có thể phân chia 1 số loại điện thờ tư gia như sau:

- Điện thờ Phật, thông thường là thờ Tam bảo (Tam thân hoặc Tam thế) và Bồ tát.

- Điện thờ Đức Thánh Trần thờ Trần Hưng Đạo và các vị quan tướng nhà Trần.

- Điện thờ Mẫu, nhưng thực chất là thờ hỗn hợp: thờ Tam tòa Thánh Mẫu và quần thần của Mẫu là chính, ngoài ra còn có Phật, Đức Thánh Trần.

- Điện thờ danh nhân văn hóa, anh hùng dân tộc.

Sự ra đời của các điện thờ tư gia trong vòng hơn 20 năm trở lại đây có một điểm chung là chủ nhân (thủ nhang) của chúng đều trải qua trạng thái bệnh tật kéo dài. Hoạt động của các điện thờ này khá sôi động, nhất là vào các ngày rằm, mùng một hằng tháng âm lịch với các hình thức phong phú tùy theo điện thờ đó có "chức năng, nhiệm vụ gì", thuộc loại hình tín ngưỡng tôn giáo nào. Tuy vậy, cũng có thể kể ra một số hoạt động chính như: Lễ tế Trời - Đất vào các dịp đầu năm, các ngày tiệc của đạo Mẫu, ngày vía Phật, lễ dâng sao, giải hạn... Ngoài những hoạt động chung của công việc tế lễ này, mỗi điện đều có hoạt động cụ thể mang tính đặc trưng riêng. Điện thờ Trần Hưng Đạo chuyên về việc trừ tà sát quỷ bằng bùa chú. Điện Mẫu coi trọng nghi thức nhập đồng hầu bóng. Điện Phật tụng kinh cầu an, cầu giải thoát cho tất cả chúng sinh.

Mục đích của những con nhang đến các điện thờ này là để tìm những lời giải đáp cho các vấn đề băn khoăn khúc mắc trong cuộc sống mà bằng cách thông thường không thể thoả mãn được. Chủ nhân của những điện thờ này cho biết, họ có thể báo trước những điềm lành, dữ, vận hạn hoặc nguyên nhân của những chuyện rủi ro đã xảy ra và cách khắc phục, chẳng hạn như: ốm đau bệnh tật chữa chạy mãi không khỏi, chuyện không ổn trong gia đình, trắc trở tình duyên ${ }^{(2)}$...

2.6. Vai trò của chùa trong đời sống tín ngữong dân gian Hà Nội

${ }^{2}$ Lê Thị Chiêng: "Sinh hoạt tín ngương tôn giáo nhìn tù một số điện thờ tu gia ở Hà Nội", Tạp chí Nghiên cứu Tôn giáo, số 5 $2004, \operatorname{tr} 61-64$. 
Chùa là cơ sở thờ tự của Phật giáo, nhưng hiện nay giữ một vị trí khá quan trọng trong đời sống và sinh hoạt tín ngưỡng của người Hà Nội.

Thứ nhất, chùa đang đảm nhận một phần chức năng của đình. Trước kia ở Thăng Long - Hà Nội, người dân thuộc bất cứ làng nào cũng sống dưới sự bảo trợ của một vị thành hoàng. Hàng năm làng thường cử hành lễ cầu phúc vào ngày sinh, ngày hóa của thần thành hoàng tại đình. Do đô thị hóa, làng thành phố, thiết chế làng bị phá vỡ dẫn đến sự suy giảm hay trở thành phế tích của ngôi đình. Vai trò bảo trợ cho cộng đồng của thần thành hoàng bị mai một theo sự tan rã của làng. Lễ cầu yên do làng tổ chức dần dần chuyển về từng gia đình tự lo liệu. Trong khi đó thì nhu cầu tâm linh, cầu sự bình an trong xã hội ngày càng cao. Do vậy, một bộ phận cư dân đã tìm đến chùa để được đáp ứng nhu cầu tâm linh này qua các lễ cầu an đầu năm, cúng sao giải hạn ${ }^{(3)}$, bán khoán, bốc bát nhang, đưa vong lên chùa...

Thứ hai, chùa cũng là một thiết chế văn hóa của làng. Trong đời sống tâm linh truyền thống, chùa dành cho phụ nữ, trong khi đình là nơi bàn việc làng, nơi lui tới của đàn ông. Cấu trúc làng bị giải thể, chùa ở nơi này nơi khác bị hoang phế, nhưng nhìn chung ngôi chùa có vận mệnh độc lập với vận mệnh của làng; khác với ngôi đình cộng mệnh với vận mệnh của làng. Trong xã hội truyền thống phụ nữ thường đến chùa, thì trong xã hội hiện đại ngày nay đối tượng đến chùa đông đảo nhất vẫn là phụ nữ

Những ngôi chùa ở Hà Nội có sinh hoạt tín ngưỡng sôi động là chùa Quán Sứ (số 73 phố Quán Sứ, quận Hoàn Kiếm), chùa Phúc Khánh (số 382 phố Tây Sơn, quận Đống Đa)...

Chùa Quán sứ là nơi đặt trụ sở của Giáo hội Phật giáo Việt Nam, do vậy các hoạt động tín ngưỡng dân gian ở chùa giới hạn chủ yếu ở lễ cầu an, cúng sao giải hạn (vào tháng giêng đầu năm), bốc bát nhang, đưa vong lên chùa, các tín đồ có nhu cầu được một nhà sư tiếp và hướng dẫn các thủ tục, lễ đặt tùy tâm.

Chùa Phúc Khánh là ngôi chùa có nhiều hoạt động tín ngưỡng dân gian: lễ cúng sao giải hạn, cầu an, bốc bát hương, đưa vong lên chùa, cắt tiền duyên, tạ mộ, bán khoán. Đặc biệt, chùa Phúc Khánh là một trong

\footnotetext{
${ }^{3}$ Theo Hòa thượng Thích Thanh Nhiễu - Phó chủ tịch Hội đồng Trị sự Giáo hội Phật giáo Việt Nam thì trong giáo lý nhà Phật không đề cập việc dâng sao giải hạn. Tuy nhiên, hoạt động này có từ lâu đời và xuất phát từ nhu cầu tín ngưỡng của nhân dân. Hiện nay, các chùa làm lễ dâng sao giải hạn để giải quyết vấn đề tâm lý, tinh thần, tín ngưỡng cho người dân. Ai có nhu cầu dâng sao giải hạn thì tìm đến chùa, đây hoàn toàn không phải là một sự bắt buộc (http://vov.vn/doi-song/dangsao-giai-han-mot-phong-tuc-dang-bi-lam-dung-587710.vov).
}

những ngôi chùa đi tiên phong trong việc xây dựng nhà để cốt và nhận được sự hưởng ứng của nhiều gia đình ở Hà Nội.

Tại chùa Phúc Khánh, ban vong đặt ở đầu hội bên trái chính điện, do vậy các lễ đưa vong lên chùa, lễ tạ mộ, lễ yên vị (đặt cốt) đều làm trước Phật điện. Các lễ cắt giải tiền duyên được làm trước ban thờ mẫu.

Khảo sát thực tế về giá của một số dịch vụ cúng lễ tại chùa năm 2017: Chị Nga (Trung Liệt - Hà Nội) cho biết theo bảng giá ở chùa Phúc Khánh thì lễ cầu an là 150.000 đồng/gia đình, lễ dâng sao giải hạn là 150.000 đồng/người không phân biệt sao xấu hay tốt, tăng giá $50 \%$ so với năm ngoái.

Mức giá tại chùa Quán Sứ là 500.000 đồng/gia đình bao gồm cả lễ cầu an và lễ giải hạn. Chùa Một Cột có mức giá lễ cúng sao và lễ cầu an là 200.000 đồng/gia đình. Có nhiều người sẵn sàng bỏ ra hàng triệu đồng để dâng sao giải hạn cho cả gia đình. Chị Hà (Thái Thịnh Hà Nội) cho biết, nhà chị có 6 người, người sao xấu, người sao tốt nhưng chị vẫn đăng ký giải hạn cho cả nhà, mong rằng sao tốt thì sẽ tốt hơn mà sao xấu thì không còn gây tác hại nữa. Ngoài ra chị cũng làm cả lễ cầu an luôn cho yên tâm.

Chị Thủy (Thành Công - Hà Nội) đăng ký dâng sao giải hạn tại chùa Một Cột chia sẻ, năm nay, vợ chồng chị đều vướng phải hai sao xấu là La Hầu và Kế Đô nên chị cũng lo lắng, đăng ký làm lễ giải hạn và cả lễ cầu an luôn để mọi việc hanh thong ${ }^{(4)}$.

\section{Tác động và ảnh hưởng của tín ngưỡng}

Thứ nhất, rõ nét nhất trên lĩnh vực này là lễ cúng $\mathrm{Vu}$ Lan trong dịp rằm tháng bảy. Tại Hà Nội, sôi động nhất là các cửa hàng bán hàng mã tại các chợ hay trung tâm buôn bán đồ mã phố Hàng Mã và cả nơi sản xuất là làng Cót, phường Yên Hòa, quận Cầu Giấy. Ngoài những mặt hàng truyền thống giày dép, mũ, nón, quần áo; hàng mã cũng có sự thay đổi khi đời sống kinh tế khá giả hơn. Những mặt hàng thời thượng như biệt thự, ô tô hạng sang, xe máy "xịn", điện thoại di động đời mới, ti vi màn hình phẳng... cũng theo đó mà hình thành. Người ít tiền chỉ cần bỏ ra vài trăm nghìn là có đủ vàng mã, quần áo, đồ đạc cho người đã khuất. Người nhiều tiền bỏ ra năm bảy triệu đồng để sắm lễ. Chủ cửa hàng bán đồ mã kiêm luôn là người tư vấn sắm lễ sao cho phù hợp, đầy đủ.

Giá trọn bộ vàng mã bình thường gồm: tiền, vàng, sớ, quần áo, giầy, dép, mũ, nón... giá từ 50.000 -

${ }^{4}$ Hồng Minh: "Dâng sao giải hạn: Một phong tục đang bị lạm dụng", trên trang http://vov.vn, truy cập ngày 23/01/2017. 
100.000 đồng, trọn bộ mã đắt tiền là từ 200.000 250.000 đồng. Ngoài ra, cùng với mẫu thời trang quần áo còn có dép sandal cao cấp, các phụ kiện đi kèm có giá bán từ 40.000 - 150.000 đồng, như: điện thoại, kính mắt, đồng hồ, dây chuyền, khuyên tai, nhẫn, ví, túi xách, khăn thời trang các loại, mỹ phẩm... Những trang phục "cõi âm" đẹp mắt của cả trẻ em, thanh niên và trung tuổi được bày bán mang nhãn mác hàng hiệu nổi tiếng như: áo phông body, quần bò ống côn, đầm ống, váy xẻ dây, váy quây, khăn quàng... có giá hàng trăm nghìn đồng/bộ.

Bên cạnh đó, một số dòng "siêu xe" để phục vụ người âm như Rolls-Royce, Maybach, Lexus... có giá khoảng 270.000 - 300.000đ/chiếc. Để cho đồng bộ, một số khách hàng còn đặt mua cả nhà lầu, biệt thự, những mặt hàng này thường có giá khá đắt, thấp nhất cũng 4.000 .000 - 5.000 .000 đ/cái, những loại to hơn có khi giá lên tới hàng chục triệu đồng.

Tục lệ đốt vàng mã đã và đang phát triển mạnh, không còn ở trong phạm vi cúng giỗ ở gia đình và chùa đền mà còn lan sang các cơ quan, doanh nghiệp. Số liệu thống kê cho thấy trung bình một năm có khoảng 50.000 tấn vàng mã được sử dụng và riêng Hà Nội đã tiêu tốn trên 400 tỷ đồng cho việc đốt vàng mã. Đặc biệt là trong dịp lễ xá tội vong nhân, việc đốt vàng mã đã bị biến thể một cách thái quá. Nếu như trước đây, mỗi gia đình chỉ mua một ít tiền, vàng hoặc một vài bộ quần áo tượng trưng để đốt cho ông bà, tổ tiên, nhưng đến thời điểm hiện tại, trung bình mỗi gia đình phải bỏ ra số tiền từ $30.000-50.000$ đồng/lễ. Với gia đình làm ăn khấm khá thì sắm lễ từ vài trăm nghìn đến hàng chục triệu đồng.

Hiện nay, nguồn sản xuất, cung cấp vàng mã lớn nhất là làng Cót (Hà Nội) và làng Đông Hồ (Bắc Ninh). Mỗi ngày ở đây tiêu thụ gần 3 tấn giấy. Tuy vàng mã là một trong những loại hàng hóa phải chịu thuế thu nhập đặc biệt, song sức tiêu thụ không hề giảm. Đại diện của Sở Văn hóa, Thể thao và Du lịch cho rằng đốt vàng mã tràn lan và hoang phí như hiện nay là một biến tướng của lối sống thực dụng thời kinh tế thị trường. Quan niệm "trần sao âm vậy" khiến nhiều người đốt mã như "hối lộ cõi âm" chứ không còn là chăm lo đến việc thờ cúng tổ tiên, tín ngưỡng. Cùng với việc tiêu tốn số tiền khổng lồ thì những vụ hỏa hoạn có nguyên nhân từ việc đốt vàng mã, đồ mã cũng gây thiệt hại không nhỏ ${ }^{(5)}$.

5 Huệ Anh: "Đốt vàng mã - đốt tiền", trên trang http://www.anninhthudo.vn, truy cập ngày 10/8/2011.
Thứ hai, tín ngưỡng là môi trường nảy sinh, tích hợp và bảo tồn các sinh hoạt văn hóa dân gian. Sáng tạo văn hóa nghệ thuật là một hình thức sáng tạo đặc thù, nó không chỉ đòi hỏi trí tuệ mà còn phải có cảm hứng, cảm xúc đạt tới trạng thái thưng hoa. Chính ở đây, một niềm tin về một thế giới huyền ảo, siêu thực, tâm linh của tôn giáo đã tạo môi trường cho sự sáng tạo nghệ thuật này. Từ tín ngưỡng tôn giáo cùng nảy sinh và tích hợp các hình thức nghệ thuật như âm nhạc, ca hát và nhảy múa. Nhạc lễ và múa thiêng tạo nên trạng thái phấn khích, vừa để con người trần tục thoát hồn, hòa nhập với thế giới thần linh, vừa để thần linh "tái hiện" trước đời sống trần tục của con người. Bởi thế trong các nghi lễ tôn giáo tín ngưỡng, với mức độ khác nhau, ít khi thấy thiếu vắng các hình thức âm nhạc, nhảy múa. Nhiều hình thức âm nhạch, các làn điệu dân ca đều xuất phát từ môi trường tín ngưỡng, như chầu văn vốn hình thành từ đạo Mẫu ${ }^{(6)}$.

Thứ ba, tín ngưỡng cũng như các hình thức văn hóa khác là hệ thống các biểu tượng. Thần thánh không phải là cái gì khác là biểu tượng tâm linh của ước vọng vươn tới cái chân - thiện - mỹ, biểu tượng của lòng yêu nước, của nghĩa lớn vì cộng đồng, vì dân tộc. Các thần linh trước hết là tổ tiên của gia tộc, dòng họ, các Vua Hùng là tổ tiên chung của toàn dân tộc, là các anh hùng dân tộc chống xâm lược..., khi sống là những người có tài, có đức góp phần vào sự nghiệp dựng nước và giữ nước, khi mất hiển linh còn là chỗ dựa tinh thần cho các thế hệ con cháu. Bởi thế, tín ngưỡng còn góp phần cố kết cộng đồng, thể hiện trên hai mặt: cộng mệnh và cộng cảm.

Cộng mệnh là sự gắn bó giữa những con người trong cộng đồng thông qua vận mệnh của cộng đồng. Vận mệnh đó liên quan trực tiếp đến việc họ cùng suy tôn, tôn thờ một biểu tượng có sức mạnh siêu nhiên, có khả năng bảo vệ cho sự tồn vong của cả cộng đồng.

Cộng cảm là sự đồng cảm về các hoạt động của đời sống tâm linh và các sinh hoạt văn hóa cộng đồng. Các sinh hoạt này không phải diễn ra ở bất cứ nơi nào, bất cứ dịp nào, mà chỉ trong môi trường lễ hội, gắn với việc thờ phụng thần linh, nên niềm hứng khởi mang tính chất tâm linh như vậy đã có tác động đến sự tham gia vào các sinh hoạt và sáng tạo văn hóa. Đồng thời, là nơi giao lưu văn hóa giữa các địa phương, vừa thể hiện được sự thống nhất, vừa mang bản sắc riêng; là môi trường chuyển giao và kế thừa văn hóa giữa các thế hệ.

\footnotetext{
${ }^{6}$ Xem Ngô Đức Thịnh (chủ biên): "Tín nguõng và văn hóa tín ngương ở Việt Nam”, Nxb Khoa học xã hội, Hà Nội, 2001, 762 - 763.
} 
Khảo sát thực tế do Sở Văn hóa, Thể thao và $\mathrm{Du}$ lịch Hà Nội và Viện Gia đình và giới thực hiện đối với 1.211 hộ gia đình tại Hà Nội cho thấy: trong hoạt động lễ chùa, 48,1\% người được hỏi tham dự các dịp lễ chính (ngày Tết, rằm tháng Giêng, tháng Bảy, tháng Tám, tháng Chạp), con số này là $20,9 \%$ vào ngày rằm, mồng một hàng tháng. 7,3\% chỉ thỉnh thoảng đến chùa nhân dịp đi công tác, du lịch và $23,4 \%$ hoàn toàn không đi lễ chùa. Trên thực tế, việc người dân tham gia lễ chùa gia tăng một phần do cuộc sống được cải thiện, các cơ sở thờ cúng được tôn tạo. Với những việc được thực hiện khi đi lễ chùa thì đặt lễ công đức "giọt dầu" cho nhà chùa chiếm tỷ lệ cao nhất $(97,5 \%)$.

Một biểu hiện khác thể hiện nhu cầu văn hóa tâm linh là việc thờ cúng tại gia. Xem xét mức độ thờ cúng, cầu nguyện tại gia trong khoảng thời gian 12 tháng cho thấy, trong số 1.211 người trả lời có $3,7 \%$ không thực hiện nghi lễ này lần nào, $4,1 \%$ cúng lễ 1 -2 lần trong năm và $2,6 \%$ thực hiện vài lần trong năm. Chiếm tỷ lệ cao nhất là những người thực hiện việc thờ cúng 1-2 lần trong tháng $(83,2 \%)$. Số liệu khảo sát cho thấy $94 \%$ số hộ có thờ cúng ông bà, tổ tiên, $8,8 \%$ có thờ Đức Phật, $46,1 \%$ thờ Ông Địa và $10,9 \%$ thờ Thần Tài... Tìm hiểu ý nghĩa của việc hành lễ, thờ cúng tại gia đối với các gia đình Hà Nội hiện nay, 70,4\% khẳng định đó là phong tục tập quán tốt, cần được giữ gìn, $48,6 \%$ cho rằng đây là những dịp để con cháu tỏ lòng thành kính với ông bà tổ tiên, $6,8 \%$ nêu tác dụng của việc thờ cúng tiền nhân, thần Phật là dịp để giáo dục con cái trong gia đình.

Khi đi lễ chùa, một số hành vi mang tính mê tín vẫn diễn ra, chẳng hạn như đốt vàng mã $(36,9 \%)$, rút thẻ $(14,5 \%)$, xin bùa $(3,7 \%) \ldots$ Đáng chú ý, có tới $77,4 \%$ thuộc độ tuổi vị thành niên đi lễ chùa để cầu phúc, cầu tài lộc, cầu tình. Tại các lễ hội, nạn cờ bạc trá hình vẫn diễn ra, từ các trò chơi ăn tiền, vui chơi có thưởng đến các sới bạc to, nhỏ. Việc tổ chức thiếu các nội dung vui chơi, giải trí lành mạnh để người dân tham gia cũng khiến nhiều người tìm đến những trò đỏ đen tự phát ${ }^{(7)}$.

Thứ tư, cần phân biệt bản chất của tín ngưỡng và việc sử dụng, thực hành hoạt động tín ngưỡng (và tôn giáo). Một nghiên cứu gần đây có thấy mối quan hệ giữa tín ngưỡng và hiện tượng "tôn giáo mới” rất đáng chú ý: Bản thân hệ thống tín ngưỡng, dù trong môi trường hiện đại, nó vẫn là không gian tâm linh, địa bàn nảy sinh (phương diện tín ngưỡng tư tưởng cũng như phương diện con người) và nuôi dưỡng các hình thức

${ }^{7}$ Lâm Vũ: "Hoạt động tôn giáo, tín nguỡng: Phong phú nhung còn bất cập", trên trang http://hanoimoi.com.vn, truy cập ngày $12 / 01 / 2013$. "hiện tượng tôn giáo mới”. Các hiện tượng tôn giáo mới có từ nhiều nguồn gốc (nhập nội, loại mới nảy sinh, tách ra từ các tôn giáo lớn vốn có trong cộng đồng xã hội... nhưng ít nhất là trường hợp ở Việt Nam, dường như tất cả các hiện tượng tôn giáo mới ấy đều cố gắng tận dụng về mặt triết lí tâm linh hoặc hình thức nghi lễ, sinh hoạt của các loại hình tín ngưỡng bản địa để phát triển... Cách phổ biến mà các hiện tượng tôn giáo mới ở Việt Nam “tìm kiếm” triết lí tín ngưỡng và hình thức sinh hoạt của cộng đồng tín ngưỡng mới hình thành này là trên cơ sở tạo ra "một thị trường biểu tượng" rộng lớn hơn trên cơ sở các nguyên mẫu - những hình thức tín ngưỡng đã có - để lựa chọn điểm chung nhất, khả năng phổ quát hơn để có thể thu hút nhận thức và tình cảm tín ngưỡng của những tín đồ mới hình thành và từng bước hoàn thiện những hình thức sinh hoạt thích hợp ${ }^{(8)}$.

\section{Kết luận}

Hiện nay, các hoạt động tôn giáo, tín ngưỡng ở Hà Nội đang phát triển phong phú, tuy nhiên, nhiều biểu hiện mê tín cũng nhân cơ hội "phục hồi", ảnh hưởng đến môi trường văn hóa chung và gây tổn hại về kinh tế. Để người dân có cuộc sống, tư tưởng, văn hóa tín ngưỡng lành mạnh hơn, đòi hỏi các nhà khoa học tư vấn, các cơ quan quản lý xây dụng chính sách văn hóa phù hợp, nhằm phát huy hiệu quả trong công cuộc xây dựng Thủ đô ngày càng giàu đẹp, văn minh./.

\section{TÀI LIỆU THAM KHẢO}

1. Huệ Anh: "Đốt vàng mã - đốt tiền", trên trang http://www.anninhthudo.vn, truy cập ngày 10/8/2011.

2. Lê Thị Chiêng: "Sinh hoạt tín ngưỡng tôn giáo nhìn từ một số điện thờ tư gia ở Hà Nội”, Tạp chí Nghiên cứu Tôn giáo, số 5 - 2004, tr 61 - 64.

3. Lê Đức Hạnh: "Hiện tượng cúng sao giải hạn ở người Việt đồng bằng Bắc bộ", Tạp chí Nghiên cứu Tôn giáo, số 12 - 2008, tr 51 - 58.

4. Đỗ Quang Hưng: "Không gian thiêng của Thăng Long - Hà Nội", Báo cáo tại Hội thảo khoa học quốc tế: "Phát triển bền vững Thủ đô Hà Nội văn hiến, anh hùng, vì hoà bình", Hà Nội ngày 7,8,9 tháng 10 năm 2010.

5. Đỗ Quang Hưng: "Mối quan hệ giữa tín ngưỡng và hiện tượng tôn giáo mới”, trên trang http://btgcp.gov.vn

6. Hồng Minh: "Dâng sao giải hạn: Một phong tục đang bị lạm dụng", trên trang http://vov.vn, truy cập ngày 23/01/2017.

\footnotetext{
${ }^{8}$ Đỗ Quang Hưng: "Mối quan hệ giũa tín nguỡng và hiện tuợng tôn giáo mói ", trên trang http://btgcp.gov.vn_
} 
7. Ngô Đức Thịnh (chủ biên): “Tín ngưỡng và văn hóa tín ngưỡng ở Việt Nam”, Nxb Khoa học xã hội, Hà Nội, 2001.
8. Lâm Vũ: "Hoạt động tôn giáo, tín ngưỡng: Phong phú nhưng còn bất cập", trên trang http://hanoimoi.com.vn, truy cập ngày 12/01/2013.

\section{Impact of belief in the spiritual life of residents living in inner Hanoi today}

Vu Truong Giang

\section{Article info}

Recieved:

$01 / 6 / 2018$

Accepted:

$10 / 12 / 2018$

Keywords:

Impact; belief; life;

spirituality; Hanoi.

\section{Abstract}

Beautiful traditional values in religious practices in Hanoi are still maintained; however, there still remain various inadequacies. The article introduces a number of religious worship and practice establishments in Hanoi, analyzes the impact and influence of belief in the lives of Hanoi residents today. 